\title{
Teaching
Anthropology
}

2021, Vol. 10, No. 2, pp. 62-68.

\section{The University versus the Academy}

\author{
Prof. Margarita Karamihova ${ }^{1}$ and Assist. Prof. Svetlana Antova ${ }^{2}$ \\ ${ }^{1}$ VelikoTarnovoUniversity "St. Cyriland St. Methodius", Bulgaria \\ Institute of Ethnology and Folklore Studies with the Ethnographic Museum, Bulgarian Academy of Science, Bulgaria.
}

\begin{abstract}
The article focuses on a conceptual difference between the institutes of the Bulgarian Academy of Sciences and Bulgarian Universities. University lecturers must be internationally recognizable with their research results and constantly master modern teaching methods and technologies. Scientists in the academy make efforts to follow the scientific tendencies, but have virtually no opportunity to go beyond academic forums and to socialize their scientific results. In the example of research and teaching of Ethnology, the lack of opportunity for young scientists from the academy to be prepared for teaching at different university degrees isconsidered. The positive and negative aspects of the Erasmus academic exchange program (as an opportunity for getting some fractional lecturing experience) is discussed in the terms of teaching experience. We also present the first and only project, held few years ago in Bulgaria, aiming to prepare young scientists from the Academy to teach Ethnology at a university.
\end{abstract}

Keywords: Bulgarian Ethnology, Higher Education, Erasmus+

\section{Introduction:}

There are not many scientific articles with a critical focus on how the educational and scientific process in Bulgaria changed after the fall of communism (Slavova, 2012). Such texts are still an exception, and it seems that the debate about the crossroads of science and education is still not completed in Bulgaria. This article focuses on a conceptual difference between the institutes of the Bulgarian Academy of Sciences (BAS) and Bulgarian Universities. Both authors represent their own academic experience at the Institute of Ethnology and Folklore Studies with the Ethnographic Museum of BAS (IEFEM) and the Veliko Turnovo University "St. Cyril and St. Methodious". The IEFEM of BAS have existed in the way it looks now since 2010 when it united from two separate institutes - the Ethnographic Institute with a Museum and the Institute of Folklore. The IEFEM-BAS is the national centre for ethnologic, folklore and cultural-anthropological research. It owns rich libraries and archives (field audio-, photo-, and video records, ethnographic diaries, and descriptions). The National ethnographic museum preserves tens of thousands of objects, exclusively representing Bulgarian traditional culture ${ }^{1}$. The wide spectrum of researchers' profiles is distributed across nine departments. The expectation is that this distributes scientific knowledge through the higher education system and scholars will engage in this themselves. As we will see later in this text, this is not the reality.

The second institution we observe here is the Department of Early-Modern and Modern Bulgarian History at the Veliko Turnovo University "St. Cyril and St. Methodius", where ethnology is studied as a separate historical discipline. There is one professor and three assistants involved in the education of ethnology studies. How four people can handle a whole educational discipline is a very reasonable question to ask given the fact that university lecturers must be internationally recognizable with their research field and constantly master modern teaching methods and technologies.

Scientists in the academy make an effort to follow their scientific tendencies but have literally no opportunity to go beyond academic forums and to share their scientific results. University lecturers are overwhelmed with lectures and find it difficult to step out of teaching, while researchers at the Bulgarian Academy of Sciences are deprived of the opportunity to integrate their scientific results into teaching. The lack of knowledge and capacity exchange between the Academy and the University is increasingly tangible in Bulgaria, but there is still no prospect of overcoming this gap. Universities suffer from this because the lack of free time from lectures prevents the lecturers from academic research activities for being carried out. The researchers of the Bulgarian Academy of Sciences suffer as they increasingly encapsulate their communication in narrow academic 
frameworks. They are not ready to meet the needs of younger generations because they lack an up-to-date look at trends in modern education.

In the example of research and teaching of Ethnology given here, the lack of opportunity for young scientists from the academy to be prepared for teaching at different university degrees is discussed. We present the first and only project, held nine years ago in Bulgaria, aiming to prepare young scientists from the Academy to teach Ethnology at a university. As an opportunity for getting some fractional lecturing experience the positive and negative aspects of the Erasmus + academic exchange program is discussed in terms of teaching experience.

\section{A Brief History of Ethnology Education in Bulgaria}

Bulgarian Ethnography and Folklore studies were shaped during the $19^{\text {th }}$ century in the process of Bulgarian Revival with a clear mission to support struggles for national independence. The heroes (or founding fathers) of the National Revival, such as Georgy Rakovski, Lyuben Karavelov and Petko Slaveykov (Valtchinova 2004: 3), were deeply involved in the promotion and development of ethnographic studies. The national idea at the time was closely connected with the concept that Bulgarians are descendants of ancient civilization; they keep and cherish their ancient culture, so they deserve to live in an independent state. Due to its appearance and development as a nation-building tool, Bulgarian Ethnology was gradually determined to be part of the historical sciences since folklore studies were nestled in linguistics. From the onset of its existence as an academic science, it became a 'national discipline'; later being exploited for ideological goals of the state or of Communist Party (1944-1989). In March 1947, following the Soviet model, a new law was passed concerning the Bulgarian Academy of Sciences (henceforth BAS). It was awarded the status of "The highest scientific institute in the country under the administration of the Council of Ministers" (Benovska-Sabkova 2008: 116, BenovskaSăbkova, Krăsteva-Blagoeva 2014: 57). According to the law, a very dangerous line was separating scholars from BAS and universities. In its attempt to keep full control on the ideology of the communist party, its leaders promoted the idea that science must be developed only in BAS (based in the capital city) and partly at Sofia University. A system to control the production of scholars, especially in the Humanities, was established. University lectures had to be taught following BAS editions.

New universities in the country emerging in the 1960s and 1970s were encouraged to invite scholars from BAS as lecturers. Most of them were first established as pedagogical colleges, responding to the need of the country to develop an educational system and to provide it with teachers. Turning into universities, former colleges suffered of lack of prominent scholars. For years those universities were dependent and controlled by academicians partisans from the capital - and it was very difficult to encourage local graduates to start a university career.

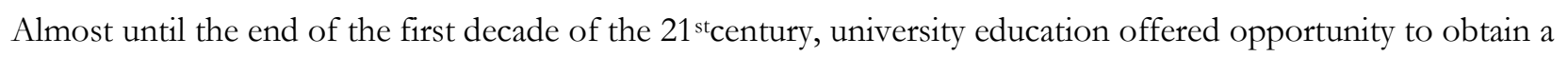
master's degree and a Ph.D. With the joining of the Bologna process and the accession of Bulgaria to the European Union, the law on higher education has changed and now there are three degrees in universities: Bachelor, Masters and Doctorate. Despite some attempts to reform, the institutes of BAS have the right to teach only $\mathrm{PhD}$ students. According to the tradition inherited from socialist times, many associate professors and professors from BAS continued to give lectures at different universities. It is important to emphasize that these were one or two lecture courses per academic year per person developed according to the teacher's academic profile.

Under the influence of a complex set of factors, such as the explosive emigration wave of the mid-1990s, the changes in the labour market, and the competition of scholarship programs at European and American universities, the number of students in Bulgaria has decreased each year. This is especially true for Ethnology students. For example, since 2012 the state subsidizes only 10 students in Ethnology at the University of Veliko Turnovo. At the University of Plovdiv their number decreased to 5 for the academic year 2018/2019. Traditionally the oldest and largest - Sofia University, has more subsidies (17 students for 2018/2019 academic year). This trend has forced university managers to sharply reduce visiting professors so that the local professors receive a huge load of lecture courses. A permanent 'savings mode' requires professors to teach many different subjects, which inevitably reduces their expertise. This fact has yet another consequence: the only opportunity for students to get acquainted with new researchers and to get a different perspective from that of their professors is to join the Erasmus+ program. Unfortunately, a large number of students work to pay for their university education and thus a long absence from the city where they study is almost impossible. If they leave work for three or more months, students have no guarantee that they will be able to find a job again on their return and pay for their education. 
While university professors are overloaded with lectures, the potential teachers from the Bulgarian Academy of Science lose access to university education. They have no opportunity to go beyond academic forums and to share their scientific results. Practically, researchers from BAS have little or no opportunity to teach in Bulgarian universities. The possibilities for them to teach come mainly through invitations from abroad. And the only one purposeful program that gives real chances for lecturing is the Erasmus+ program. Therefore, we will now pay special attention to the participation of Bulgarian scientists from BAS into the existing E+ opportunities for teaching.

\section{Erasmus+ from the Point of View of the Academy}

Since 1 January 2014, Erazmus,$+{ }^{2}$ a European program for education, learning, youth and sport, has been established as an extension and unification of seven programs that had existed until the end of 2013: Long life learning programme (Erazmus; 'Leonardo da Vinci'; 'Comenius'; 'Grundtvig'; Study visits); Youth in action; Erazmus mundus; Tempus;Alfa; Edulink; and bilateral cooperation programme EACEA (European Education and Culture Executive Agency. The Erasmus+ programme continues. The budget of 14,7millions of euros, $40 \%$ bigger than the investments before, looked promising for the engagements of the European Union into development of these fields. All member states of the European Union, Iceland, Liechtenstein, and Norway as states - members of the European Economic Area (EEA) and Turkey and Republic of Macedonia as candidatemembers of the EU are included into the Erazmus+ programme.

As a higher education institution, the Bulgarian Academy of Sciences successfully applied for the Erasmus University Charter, which gives access to the activities envisaged in the program.

The Mobility Project within the Program includes:

1. Mobility of $\mathrm{PhD}$ students, regardless of the form of training, for minimum three and maximum twelve months to attend courses at the host higher education institution or to develop a dissertation without paying for this academic charge. The program grants monthly financial assistance, within the duration of the doctoral studies. PhD students continue to receive their scholarship at the Bulgarian Academy of Sciences.

2. Mobility of scientists and employees for the purpose of lectures and training for a minimum of two days to maximum of two months without counting days on the road. Usually, the program grants a daily allowance for five days and travel stipend. A prerequisite for applying for mobility is an interinstitutional agreement between BAS and a host university, a request for which can be made at the Erasmus office if there are established contacts.

This short description of Erasmus + gives a relatively clear picture of the opportunities that can be achieved. Beneficiaries can gain a variety of useful experience including teaching experiences. The application system is unified for all BAS members and every year a regular call for applications is submitted. All applications are examined by a commission at the Head Office of BAS. Candidates have the responsibility to make preliminary negotiations with the host institutions and to promote their teaching program. Typically, it includes a proposal of four lectures within the competency of the candidate. Each lecture should be designed for two academic hours. Additionally, the candidate sends a professional CV that proves her/his previous experience in the relevant field.

The Commission at the Head Office of BAS makes decision which candidates to approve for the respective annual quota. The main quota cannot be filled usually and an additional call for applications is made each year. At these second calls people usually apply, under the same conditions, who have been rejected on first application and new applications are re-examined to fill vacancies. Although the applications are considered by an independent commission, the decision as to which of the candidates is to be approved and who is rejected is influenced to a large extent by a subjective factor. It is hardly possible to clearly draw the criteria on which applications are assessed only from the preliminary teaching programme and a professional CV. Often, a rejection factor is, for example, a previous application where an approved candidate has failed to complete their travel. This approach does not consider the reasons that led to their inability to do so. Moreover, the new application of the same candidate may contain a completely different cycle of lectures compared to the previous application. There comes one additional weakness of the management of the Erasmus+ program in BAS. Although the profiles of partner institutions are usually similar, the choice of lectures is left entirely in the hands of potential candidates. This does not take into account the needs of the host institution itself: what students need to learn from their visiting lecturer is not a question for the evaluation of the applications in BAS. By this 
we would like to emphasize that there is no objective criterion that would facilitate the selection committee itself to evaluate if a proposal meets the real needs of the host institution. The prior consent of the host institution is the only one that is being considered at the application stage, but in many cases this is dictated by the need for the negotiated quota to be fulfilled.

Although the freedom of the candidate lecturer to choose the place and the institution to attend is a positive factor. Here, immediately comes a further, albeit informal, restriction that is taken into account in subsequent applications. There is an unwritten rule that once you visit a host institution, you cannot apply for it next year. According to the BAS rules, re-applying to the same institution will automatically give priority to another candidate who has not yet been there. Even if there are no candidates for the same host institution, another application will be approved for a different place because of the annual quota. For BAS members it is virtually impossible, in the framework of the Erasmus+ program, to consistently build useful teaching experience, considering the lectures offered by the guest lecturer to meet the needs of the host audience. It has already been pointed out that the candidate lecturer chooses, based on her/his own experience and competence, what teaching programme to offer. As a rule, at the Bulgarian Academy of Sciences, what is offered as a teaching program is entirely based on the research conducted so far and the lecturer presents their summarized results. This poses a question, is the results of a study actually a teaching product? What is provided as a lecture very often is just an extended version of a report. Usually, BAS researchers have experience mostly through their appearance at scientific forums, where they present their results on a given topic within a limited time. The lack of knowledge and experience in teaching, especially for young scientists, limits their ability to develop their research in the direction of transferring knowledge, rather than just communicating curious results from a unique piece of research.

Erasmus + is designed so that it cannot provide the necessary experience and abilities. It only gives a platform for expression and probability in the years of experience gained in it, for each to develop their own abilities to transform their own research results into a qualitative teaching program. This is a self-learning process for the scientists in the Bulgarian Academy of Sciences system. This process could be long, slow, and unclear as it is, based only on the individual's ability to estimate and analyse their own activities. The gained experience of visits as Erasmus+ lecturer can be useful for the transformation of the research results into lectures. The decision of the administration every time to attend different host institutions carries the risk that the proposed teaching product does not meet the expectations and needs of the next host institution. This requires an additional effort from the candidate lecturer to examine the institution they are applying for and to find the academic areas where their proposed program is best suited. The experience so far shows that this is doubtful. The newest report on a comparative analysis of current practices in Erasmus Staff mobility at European higher education institutions shows that one of the most discouraging factors include poor promotion: respondents lamented the lack of information about partner universities and about the programme (Cannizarro S., S. Ball\&N.Rachel-Naseem, 2018: 4).

The frequency of participation of both young researchers and experienced ones from BAS into Erasmus+ mobility programme is considerable too for developing teaching experience. In the most optimistic scenario, this may happen once in a year, and the likelihood of non-approved follow-up is always there, and very often this happens. Again, the lack of objective criteria on which a teaching program is approved or rejected suggests a researcher is not able to practice teaching on a regular basis under the Erasmus+ programme. As has already been mentioned, even in the most optimistic version when one lecturer is teaching in a different institution every year, this gives them the experience of just four academic lectures (per year). In comparison with the university professors, one can realize how small this experience is, although it is extremely useful in the general terms of the Program. And given the fact that each cycle of lectures each year must be consistent with the audience of the host institutions, it must be concluded that it is almost impossible for a BAS researcher, even within a rather long period of time, to accumulate teaching experience, which a university lecturer acquires in just one of his lecture courses during an academic year.

\section{Erasmus+ as One More Opportunity}

Unlike the centralized and highly restrictive system of administration of Erasmus + at the Bulgarian Academy of Sciences, the Erasmus + Office of the University of Veliko Turnovo offers an opportunity to develop a longterm strategy. Contracts between universities most often involve the exchange of two lecturers and two students per year. The choice of lecturers and students depends on the coordinator of the particular contract (professor or assistant professor), who is able to see the prospects for long-term planning. This can ensure the sustainable development of partnerships between university lecturers and the development of different successful projects. 
The possibility of teaching mobility can serve as a rescue belt in cases where the university budget is very small and professors cannot rely on funding travel abroad. Let's take a look at the following example:

A research field that has been challenging ethnologists for 30 years now is the study of socialism. We deeply believe that the knowledge and understanding of the cultural models of socialist countries are important in order to understand the processes that are developing in the post-socialist countries today. Both as scientists and as citizens we believe that university courses should be taught Ethnology of socialism as well as Ethnology of postsocialism. Therefore, in the curriculum of the Ethnology courses at the University of Veliko Tarnovo, since 2012 a compulsory study of socialism is included, and post-socialism can optionally be studied. The experience of participating in academic exchanges shows that the interest in socialism issues is equally high in both the postsocialist countries and the countries that have no experience with socialism. The fact that our students were born long after the collapse of socialism determines the framework of basic knowledge to be given to them.

In 2016, I professor Karamihova was invited by the respected Professor Ljupco Risteski of the University of Skopje, Macedonia, to participate as a lecturer at Ethnography of Socialism Spring School. The concept of organizing an International Spring School, which is exempt from institutional coercion, raises the issue of funding. How to provide lecturers from relatively poor countries without funding? Our previous experience has suggested one of the possible solutions: to use opportunities offered by the Erasmus+ program. The academic exchange agreement between the two universities - the "St. Cyril and St. Methodius" University of Veliko Turnovo and the "St. Cyril and St. Methodius" University of Skopje - created an opportunity for long-term planning of the lectures and participating lecturers for the spring school. In comparison, the exchange agreement between the University of Skopje and the Institute of Ethnology and Folklore with the Ethnographic Museum of BAS is still pending despite the procedure starting a few years ago.

For each subsequent year, topics and highlights were specified, depending on which countries the students will visit the Spring School from and what their interests in Anthropology and Ethnology are. Every year we consult with colleagues who are interested in the study of socialism and invite lecturers to present their cycle of lectures to the students. This ensures that the logic of the curriculum is respected, and the host institution only benefits from it. This small example demonstrates how long-term strategies can be developed and opportunities for creating common teaching programs through participation in the Erasmus+ program can be developed. My (Antova) personal attempt to apply for the International spring school through our Erasmus + office two years ago was unsuccessful. My application was rejected. Reasons were not stated.

\section{An Attempt to Break the Scheme}

More than ten years ago, a project was initiated at the Institute of Ethnology and Folklore with the Ethnographic Museum (former Ethnographic Institute with Museum). The reason for implementing this project is rooted in the identification of some serious shortcomings of the educational system in Bulgaria. Young people who choose to work in the field of science and higher education do not get sufficient practical training for their future career. The Bulgarian higher education system offers training for primary and secondary school teachers but not for university teachers. Young researchers do not know how to develop scientific projects or how to compile a collection of scientific articles. The rules for presenting papers at scientific conferences, speaking in front of an unknown audience abroad or even of dressing appropriately are also important elements, which should not be learned by trial or error. The need for teaching these and many other practical skills formed the rationale for this project.

The project 'European Dimensions of Culture and History of the Balkans (Training Program for Post-Doctoral Students and Young Researchers)' was financed by the Human Resources Development Operational Programme, Granting of Free Financial Support Scheme: BG051PO001/07/3.3-02 'Support for the Development of Doctoral and Post-Doctoral Students and Young Researchers'. It was implemented by the Balkan Ethnology Department of the Ethnographic Institute and Museum (now IEFEM) at the Bulgarian Academy of Sciences (BAS)in partnership with a team from the Institute of Balkan Studies, BAS. The project was launched on 16 June 2008 and completed on 15 June 2010. The initiator and manager of the project was Margarita Karamihova.

The main goal of the project was improving the quality of education and facilitating access to it; creating good conditions for the training of post-doctoral students as a basis for sustainable development and competitiveness; establishing Bulgarian humanities as a part of the European regions of knowledge. 
The core activity of the project for each participant was the development of an own lecture course. Under the guidance of leading scholars in Balkan history and Ethnology, the post-doctoral students developed university courses and accompanying readers. Senior research fellows at the two partner institutes were lecturers and mentors. They were tutoring every one of the 18 post-docs, sharing their experiences as university lecturers. Each university course was presented to the other participants in the project and reported at the Academic Council meetings at the institutes.

The final activity of the project was writing an article on the subject of the newly developed lecture course. Each post-doctoral student was encouraged to use the available resources and to seek consultation and advice from all the other participants in the project. A collection was published in English and Bulgarian (Karamihova, 2010). The idea was to make it accessible to the widest possible audience in Bulgaria and in the common European area of knowledge. The post-doctoral students went through all stages of compiling a paper collection - from the writing of an article to editing, negotiating with the publisher, approval of the layout and first contact with the published collective work.

Nine years later, we can prove that this project was a success. We will start by saying that post-doctoral students Zdravko Zdravkov and Gergana Georgieva have become lecturers at the University of Veliko Turnovo (as assistant and as associate professor nowadays) and Meglena Zlatkova is associate professor at the University of Plovdiv. At 2011 Karamihova became full professor at the University of Veliko Turnovo. All other participants in the project successfully develop their career using the knowledge they have gained.

\section{Conclusion}

This text outlines a small piece of the big puzzle of the state of teaching Ethnology in Bulgaria nowadays. We entitled the article this way because a new/old trend appeared in the winter of 2019. An offensive is unofficially run for the return of the old incontestable leadership positions of the institutes of the Bulgarian Academy of Sciences. Despite the fact that the state has the same standard requirements for professors at universities and at the BAS, the idea is that "the elite science" is made only in the Academy. The question arises: What will this science serve for? Maybe the answer will be found if we will seek ways for young scientists to promulgate their knowledge through systemic teaching, for example by signing national Erasmus + contracts, as it is long lasting practice for example in France. On the one hand, this will give a chance to young scientists from the Bulgarian Academy of Sciences to transfer and share their knowledge, on the other hand, it will free a time space for the university lecturers to implement their scientific research and work on their academic development. Instead, of constantly opposing the Academy versus the University, it is of mutual interest to seek ways to fill the gap between them.

\section{Notes}

${ }^{1}$ http://iefem.bas.bg/en/

${ }^{2}$ More details can be found on the Erasmus+ programme guide: https://ec.europa.eu/programmes/erasmusplus/programme-guide/part-a en and for PDF: https://ec.europa.eu/programmes/erasmusplus/resources/documents/erasmus-programme-guide-2019 en

\section{Disclosure statement:}

No potential conflict of interest was reported by the authors.

\section{References}

Benovska-Săbkova, M. (2008) 'Struggling for New Paradigms: Personalities and Institutions in Bulgarian Ethnography and Folkloristics (1944-1989)'. in: V. Mihailescu, I. Iliev, S. Naumović (eds.), Studying Peoples in the People's Democracies II. Socialist Era Anthropology in South-East Europe, Berlin: LIT, pp. 115-136

Benovska-Săbkova, M. and E. Krăsteva-Blagoeva (2014) Bulgarian Ethnology in the Wake of 1989: Ideas, Practices, Institutions. Ethnologia Balkanica, issue: 17: 55-83

Cannizarro, S., S Ball. and N Rachel-Naseem. (2018) 'Report on a comparative Analysis of current practices in Erasmus Staff mobility at European HEIs', Middlesex University from: 
Teaching Anthropology 2021, Vol. 10, No. 2, pp. 62-68.

https://www.realise erasmusplus.fr/sites/default/files/KM3668 MDX Uni REALISE report v5 DIGITAL.pdf

Karamihova M. (ed) (2010) Readings in the history and culture of the Balkans. In support of University Teaching. Publisher: Paradigma Publishing House

Slavova, P. (2012) 'Post-Socialist Higher Education in the Mirror of the Socialist Past: The Case of the Discipline of Sociology at Sofia University St. Kl. Ochridski', Sociological Problems, vol. 3-4, pp. 67-96

Valtchinova G. (2004) 'Folkloristic, Ethnography, or Anthropology: Bulgarian Ethnology at the Crossroads', The Journal of the Society for the Anthropology of Europe Volume 4, Number 2, Fall/Winter: 2-18 